\title{
Logistical Hubs as a Means of Regional Growth: The Case of the Vaal Logistical Hub
}

\section{Wynand Grobler}

School of Economic Sciences, North-West University, Vanderbijlpark, South Africa

Email: Wynand.Grobler@nwu.ac.za

\section{Diana Viljoen}

School of Economic Sciences, North-West University, Vanderbijlpark, South Africa Email: Diana.Viljoen@nwu.ac.za

\section{Doi:10.5901/mjss.2014.v5n21p229}

\section{Abstract}

The purpose of this article is to investigate the importance of transport infrastructure and establish a link between transport infrastructure and regional growth. The impact of several international logistical hubs is used as a yardstick to determine the potential impact that the proposed Vaal Logistical Hub (VLH) would have on the Vaal region. Potential stakeholder interest in a logistical hub was tested through a participant survey and a freight forwarder survey. The respondents indicated that they would participate in the activities of the VLH and fully support its establishment in the Vaal region. They perceive that the VLH would lead to higher levels of job creation, higher business confidence and industrial development. By establishing a logistical hub in the Vaal region, regional economic growth will be experienced as well as the creation of between 28000 and 48000 jobs.

Keywords: logistical hubs, regional growth, job creation, Vaal region.

\section{Introduction}

One of the main goals of a developing nation like South Africa is the maintenance and improvement of the living standards of its citizens. According to the Department of Transport (DoT, 1998) the achievement of this goal depends on the nation's ability to increase capital investment, labour productivity and the continuous improvement of those industries in which it competes on a global scale.

As an economy that functions predominantly on primary and secondary economic activities, South Africa is forced to employ various strategies that focus on the inherent economic strengths of regions within the country. Jourdan (1998) emphasised the importance of these regional development initiatives as a means of enhancing the economic potential of the region concerned. However, investment in a particular industry or activity is not always the catalyst for economic growth and exogenous influences, such as Blue IQ initiatives, are often needed to provide the push necessary for change to occur.

Infrastructure that is both efficient and productive is one of the key features of a growing economy. According to the DoT (1998), investing in assets such as road and rail networks would enable regions and localities to enhance levels of development within their borders and thereby, aid the creation of wealth and economic opportunities through increased competitiveness. Transport infrastructure is generally seen as an enabling industry as it is a catalyst for growth and guarantees regional, national and international integration. Transport infrastructure has the capacity to ensure that national and social objectives are met, thereby becoming a critical input for those industries outside of the transport industry.

Rodrigue (1998) stated that when transport systems are efficient the economic and social benefits would have several positive multiplier effects, such as better accessibility to markets, enhanced competitiveness, job creation and endogenous investment within the region. A deficient transport system reduces capacity, reliability and accessibility of an industry and retards any avenues of possible growth.

Havenga (2010) indicated that freight transport networks are one of the key challenges that South Africa must overcome in order to improve competitiveness, create sustainable development initiatives and ensure upliftment of impoverished citizens. The Presidency (2007), in its Accelerated and Shared Growth Initiative for South Africa (ASGISA) and Finance Minister Pravin Gordhan (Gordhan, 2010) have both stated that the inefficiency and insufficient capacity of 
the national freight and logistics system is one of the factors that hamper South Africa from achieving sustainable economic growth. The Council for Scientific and Industrial Research (CSIR, 2012) stress the importance of addressing skills shortages and misalignment in the transport sector so as to enhance public-private partnerships (PPPs) and ensure an efficient transport sector that facilitates regional development and co-operation.

Transport infrastructure links the factors of production between producers and consumers and plays a key role in reducing the cost involved in transporting goods from producers to the relevant markets and will also enhance the reliability of shipping goods from South Africa to its trading partners. South Africa's economic activities are predominantly primary and secondary in nature. The transport system within an economy essentially supports the transition from a manufacturing to a service driven economy.

The purpose of this paper is to determine the effect that a logistical hub would have on industrial development within a region characterised by resource-based, capital-intensive industrial activities.

\section{Background to the Study Area}

The Sedibeng District Municipality (SDM) comprises the Emfuleni, Midvaal and Lesedi municipalities and is the second largest municipality and the fourth largest population in Gauteng (Sedibeng District Municipality, 2011). It includes the towns of Vereeniging, Vanderbijpark, Meyerton and Heidelberg as well as the townships of Sebokeng, Bophelong, Sharpevill, Evaton and Ratanda.

\subsection{Overview of the Sedibeng District Municipality}

\subsubsection{Economic growth and sectoral structure of the Sedibeng economy}

SDM is the fourth largest contributor to the Gauteng economy. Over the period from 2006 to 2011, the Sedibeng economy has experienced an economic growth rate of 3.1\%. However, the annual growth rate was measured as $0.8 \%$, which is well below the proposed annual growth rate of $8 \%$ (Sedibeng District Municipality, 2011).

More than half of the economy of the region is dominated by the services sector (57.2\%) with the largest contributor being manufacturing at $30.8 \%$ of regional gross domestic product (GDP). Manufacturing activities comprise two main sub-sectors, namely fabricated metal (with Arcelor-Mittal, Cape Gate Davsteel and Samancor being the largest producers of metal and metal products in the region) and chemicals (Sasol being the only firm in this regard). Manufacturing will remain the dominant economic activity within the region for the foreseeable future despite its $6 \%$ decline over the period 2006 to 2011 (Sedibeng District Municipality, 2011).

\subsubsection{Employment trends}

Despite the $0.8 \%$ decline in unemployment between 2006 and 2011, there is a need for a project that would address employment in Sedibeng (Sedibeng District Municipality, 2011). Global Insight (2011) has recorded unemployment in the district as $40.4 \%$, which is amongst the highest in Gauteng. A possible cause of this increase is the job shedding undertaken by Arcelor-Mittal. Clearly, a significant change to the employment structure in any of the dominant subsectors of the Sedibeng economy will have a profound impact on its inhabitants.

\subsubsection{Economic development in Sedibeng District Municipality}

The poverty rate for the region has declined from 44\% in 2001 to 38\% in 2010 (Sedibeng District Municipality, 2011), which is still higher than that of the entire province. The poverty rate for Gauteng province has declined form $30 \%$ to $29 \%$ over the same period. The Gini co-efficient for the district is 0.68 , which indicates that there is a high degree of inequality present in the population. However, there has been a 3.4\% overall increase in the level of education in the district, with the largest growth experienced in tertiary qualifications (Sedibeng District Municipality, 2011).

\section{The Relationship between Transport Infrastructure and Economic Growth and Development}

Transport infrastructure has often been the catalyst for economic and social transformation (Rodrigue, 1998). Bartolomeu Dias, Christopher Columbus, Henry Ford and Wilbur and Orville Wright ushered in new eras of trade and indirectly enhanced globalisation through the use and development of transport and transport infrastructure. 
In developing nations, the lack of transport infrastructure has been cited as a cause of higher transport costs and unreliable supply chains. As a counter to this, the DoT (2005), in the Moving South Africa strategy, envisioned a transport sector that contributes to sustainable economic growth and development. Investment in the transport sector would link productive units and underutilised agglomeration economies to the international and domestic markets, thereby promoting competition and enhancing productivity. Efficient and productive transport infrastructure is seen as reducing logistics costs which would reduce the cost of living and production through excess capacity. Transport should contribute to South Africa's socio-economic development in the most sustainable manner possible and must eradicate operational bottlenecks in the country.

As part of the transport objectives of the Millennium Development Goals (MDGs), the UN cited reduced cost and efficient transportation systems for landlocked regions and countries as one of the targets that must be met by 2015. As such, the DoT (2005) outlined the role of the transport sector, which holds true for freight transport, in achieving, amongst others, the MDGs mentioned above. The roles are as follows:

- Transport infrastructure is a fundamental key in promoting economic growth and development within developing countries. Most developed nations have highly advanced logistics systems and this has provided the countries concerned with the drive to achieve greater economic growth through transport infrastructure investment;

- Transport infrastructure is a means to achieve the harmonisation of transport systems throughout a particular region;

- Freight logistics has contributed to the economic growth of regional trading blocs and agreements such as SADC, New Partnership for Africa's Development (NEPAD), Mercado Común del Sur (MERCOSUR) and the African Growth and Opportunity Act (AGOA); and

- Reliable transport services are required to ensure the supply chain competiveness of domestically produced goods.

Gibb (2007) outlined the relationship between transportation and the economy. As transport infrastructure becomes efficient and reaches higher levels of investment, benefits such as increased capacity, efficiency and reliability will occur. These benefits, in turn, create transport time and cost savings as well as the possibility of business expansion. These productivity gains are then transferred to increased competitiveness which will ultimately increase economic growth within a nation.

\subsection{Regional perspective}

Rodrigue (1998) indicated that economic development has become increasingly reliant on relationships across economic regions than those amongst economic resources. Jourdan (1998) highlighted the need for targeted programmes which focus on regions that have the greatest potential for development. When seen as a factor of production, any change in the transport sector would have a substantial impact on cost and performance of industries. These impacts are provided with a spatial perspective (Rodrigue, 1998):

- Geographical specialisation - in the case of the Vaal region (known for specialisation in the petro-chemical and steel industries), geographical specialisation is supported by an efficient transport system and promotes economic productivity. Comparative advantages accrue to the regions concerned;

- Large scale production - an efficient transport system which offers time and cost savings as well as enhanced reliability, enables goods to be transported over longer distances. This promotes economies of scale as larger markets can be accessed;

- Increased competition - an efficient transport system enables potential markets to be opened to the producer and thereby increases competition within the market concerned; and

- Increased land value - In the case of the proposed site for the VLH, the utility for the area would increase as a result of the higher incidence of economic activity taking place within the Vaal.

The Organisation for Economic Cooperation and Development (OECD, 2002) identified the following aspects as possible spillovers resulting from investments in transport infrastructure:

- Accessibility - regional accessibility is improved which, in turn, increases the market size for manufacturing activities as well as labour and tourism. The increased market size will lead to increased competition and possible centralisation of economic activity;

- Employment - regional employment is particularly important in the Vaal region. The maintenance and operation of the VLH would increase employment through both created and relocated jobs. This would depend 
on the level of traffic through the hub; and

- Efficiency - for any industry within a given region, the time and cost savings as well as the increased reliability and accessibility would lead to productivity gains that could be achieved through enhanced production and distribution.

\section{Transport Infrastructure in Gauteng}

Gauteng remains the main industrial hub of South Africa and contributes 33.9\% to the overall GDP of the country (Stats SA, 2010). According to the DoT (2005) the projections from 2003 to 2020 show possible capacity constraints that must be addressed in order to maintain a competitive position in the global economy. Moving South Africa (DoT, 1998) has identified 3 strategic actions that are required in the freight transport system:

- Build density in the transport system by enhancing the capacity of existing freight corridors. This is done by improving infrastructure and attracting investment to the transport system;

- Create economies of scale within transport modes by increasing the competitiveness of transport nodes and offering increased capacity where economically sustainable; and

- Improve levels of competition by improving integration amongst the various modes and building an industry platform that drives the process of innovation and differentiation.

The CSIR (2012) noted that the largest growth in freight transported in South Africa was recorded along the Western Cape-Gauteng corridor and the Kwazulu Natal-Gauteng corridor. The estimated increase amounted to 15.9\% (road and rail combined) between 2010 and 2012.

The VLH would meet the requirements stipulated by the Moving South Africa (MSA) (DoT, 1998) strategic action plans. The VLH would be connected to two of the major freight corridors in South Africa, namely the Gauteng - Durban (running along the N3 highway), and the Gauteng - Cape Town (running along the N1 highway) corridors. Several opportunities exist in these corridors, which the VLH would utilise to the benefit of the region at large.

\subsection{The Gauteng-Durban (N3) corridor}

According to the DoT's National Freight Monitoring Framework (DoT, 2007) the Durban to Gauteng line is the most important rail freight line in South Africa. The transport of goods by road and rail in the corridor is mostly done through containers. The DoT (2005) highlighted certain strategic issues that are facing the corridor:

- MSA projected the capacity of the corridor to reach 57 million tons by 2020;

- As of 2004, the corridor was already close (53 million tons) to the 14-year capacity projected by MSA and is expected to grow by $35 \%$ by 2020 ;

- The operational capacity of rail networks has been established at $20 \%$ and is constrained by a lack of freight lines and trained personnel to handle the backlog;

- Delays at marshalling yards (Durban port and City Deep) decrease the competitiveness of rail;

- Asset age at terminals (such as City Deep) reduces the efficiency of rail; and

- Traffic is not evenly balanced along the route.

According to Pienaar (2005), the total number of containers transported along the corridor was estimated at 1603924 (in 2004). Of these, 138871 was transported by rail and 1465053 was transported by road. The predominant mode of transport is road as it is projected that road freight transport will increase by $82 \%$ from 2004 until 2020. Seeing as though the rail line between Durban and Gauteng is only utilised at $30 \%$ of its total capacity, this severely constrains road networks along the corridor.

The projected container volumes that will be moving along the corridor will reach absolute capacity by 2035 (no growth in 2050). A move to intermodal transport and the increased utilisation of rail as a means of transport is essential. The use of rail, being a more energy efficient means of transport, would decrease transport costs along the corridor. This in turn would increase efficiency and productivity. The VLH would be able to utilise the excess capacity of the N3 corridor rail facilities.

\subsection{The Gauteng-Cape Town (N1) corridor}

The NFMF (DoT, 2005) has identified the Gauteng-Cape Town corridor as being part of the North-South corridor which runs from Cape Town to Harare. Containers are transported by both road and rail between the relevant ports and 
Gauteng. However, major capacity constraints at City Deep have caused bottlenecks in road freight transport. The DoT (2005) has identified the following strategic issues facing the corridor:

- Of the 19 million tons of freight transported along this corridor, more than 17 million is consumed locally;

- The capacity constraints facing ports in Cape Town are not as dire as those in Durban (where urgent expansion is needed) and expansion can take place between now and 2020;

- Rail is underutilised; and

- Road corridor capacity is constrained by single lane traffic along a portion of the corridor.

The VLH would be the perfect project to reduce the capacity constraint which exists in this corridor. The excess carrying capacity of existing rail networks can also be utilised by the $\mathrm{VLH}$. The existing industries in the Vaal would be able to gain greater access to the major transport routes in the province, thereby enhancing local capacity, competitiveness and welfare.

\section{The Importance of Logistical Hubs}

In his 2005 book, "The World is Flat", Thomas Friedman postulates that, in terms of commerce, the playing field is level and all competitors (worldwide) have an equal opportunity. This would be an adequate assumption if the ceteris paribus principle was applied across all nations and across all industries of the world. South Africa, like other developing nations, is at a distinct disadvantage when compared to the developed economies of the word, such as Japan, the United Kingdom (UK) and the United States of America (USA), as South Africa has a lack of intermodal and multimodal integration and transhipment facilities.

Multimodal transport is defined as a means of shipment that combines multiple variations of the different transport modes (air, rail, sea and road). The freight forwarder, in determining the lowest possible cost to the producer, will combine the modes of transport in the most cost efficient configuration. DeWitt and Clinger (1999) defined intermodal transportation as the use of only two or more modes to move a shipment of goods from their point of origin to their destination. The existence of both multimodal and intermodal means of transportation is a critical factor in the successful execution of value chains within a region and will also bring about regional spillover effects to an economy.

Despite the benefits of intermodal and multimodal transportation, several key challenges still exist. These are (DoT, 2005):

- Economic challenges - such as inefficient intermodal planning, lack of appropriate facilities and infrastructure.

- Human resource challenges - includes poor environmental quality at current intermodal facilities that discourage investment and a lack of adequate security.

- Stakeholder \& customer challenges - no customer service focus as the entity is seen as purely infrastructural and not service-based.

- Operational challenges - capacity underutilisation and low productivity, unreliability at existing facilities.

- A logistical hub is seen as a platform for both multimodal and intermodal transportation that overcomes these key challenges. Humphrey and Schmitz (2000) defined an inland port as a site that is located away from the traditional land, air and coastal borders. The port would facilitate international trade through investments in multimodal transport infrastructure and by promoting value-added services as goods move through the value chain. Transport activities within these hubs are managed so as to keep costs down and simplify the movement of goods from producers to consumers.

Goh (2008) has identified the possible drivers for the selection of logistical hubs as a means of regional development and growth:

- Demand side forces such as improved accessibility, enhanced reliability, benefits of intermodal transport, enhanced connectivity between industry and consumer;

- Supply side forces, which include reduced transport costs, economies of scale and scope, upstream and downstream industries realise benefit of co-operation, risk reduction through consistent service; and

- Enhanced efficiency, service quality and production capacity.

\subsection{Overview of the proposed project}

The proposed Vaal Logistical Hub (VLH) would comprise the following projects: the Vaal Inland Container Depot (VICD), which would serve as a means of expanding existing infrastructure and promoting the establishment of new downstream industries in the manufacturing sector of Sedibeng. The Vaal International Airport (VIA), as part of the VLH, would 
facilitate the transportation of cargo to and from the rest of the Gauteng region. Both of these initiatives combined would promote the establishment of possible clustered downstream industries, known as the Vaal Industrial Development Zone (VIDZ), relating to the two infrastructural development projects and would also promote the relocation of existing industries in order to shorten the distance between supplier and end-user.

These three undertakings would facilitate the expansion of trade and industry within the area as well as supplying various socio-economic benefits to the inhabitants of Sedibeng. It would serve to regenerate the flagging manufacturing sector by providing a means of opening up the economic potential of underutilised industrial and infrastructural capacity by targeting strategic industrial assets that are important to the growth of the regional economy (VRG, 2006).

\subsection{The impact of logistical hubs: case studies}

As the VLH is only a proposed project to enhance LED within the Vaal region. Further investigation into the actual number of employment opportunities created and the increase in investment within the region would have to be done. However, this would be a high-cost undertaking. The VLH is a similar project to those discussed in Table 1. By taking the economic impact of these domestic and international logistical hubs into account, it can be postulated that the VLH would have a similar impact on the economy of the Vaal region. Table 1 highlights the projects' impact in terms of job creation and investment within the region of implementation. Infrastructure available to the hubs has also been highlighted.

All of the projects discussed have access to road, rail and airport terminals. On average, all of the projects would create around 26000 direct jobs. Direct employment opportunities are those created directly to serve the operational needs of the hub concerned. According to Els (2010), Tambo Springs, which has access to the same road and air transport networks as the VLH, would create anywhere between 37000 and 57000 jobs (depending on downstream activities that locate to the region). Of these employment opportunities, 28000 to 42000 would be from logistics operations alone, while 9000 to 14000 would result from related activities located in the VIDZ. During the first phase of the project, it is estimated that $\mathrm{R} 1$ billion in investment will be generated within the region.

The effect of Tambo Springs on its locality would be mirrored by that of the VLH on the Vaal economy. The same number of jobs can be generated by the VLH and, given that the VLH is within close proximity to rail facilities, the effect of the project would be further reaching than that of Tambo Springs. As indicated by the DoT (2005), the major freight corridors are expected to grow by 38\% (Gauteng-Durban corridor) and 40\% (Gauteng-Cape Town corridor) respectively by 2020. With its large manufacturing base, the Vaal region would be in a prime position to utilise this growth opportunity in order to reduce transport costs, enhance competitiveness and expand local market access by establishing the VLH. By establishing the VLH, an average of 26000 jobs will be created. This would go a long way to decreasing unemployment in the region.

Table 1: Economic impact of domestic and international logistical hubs

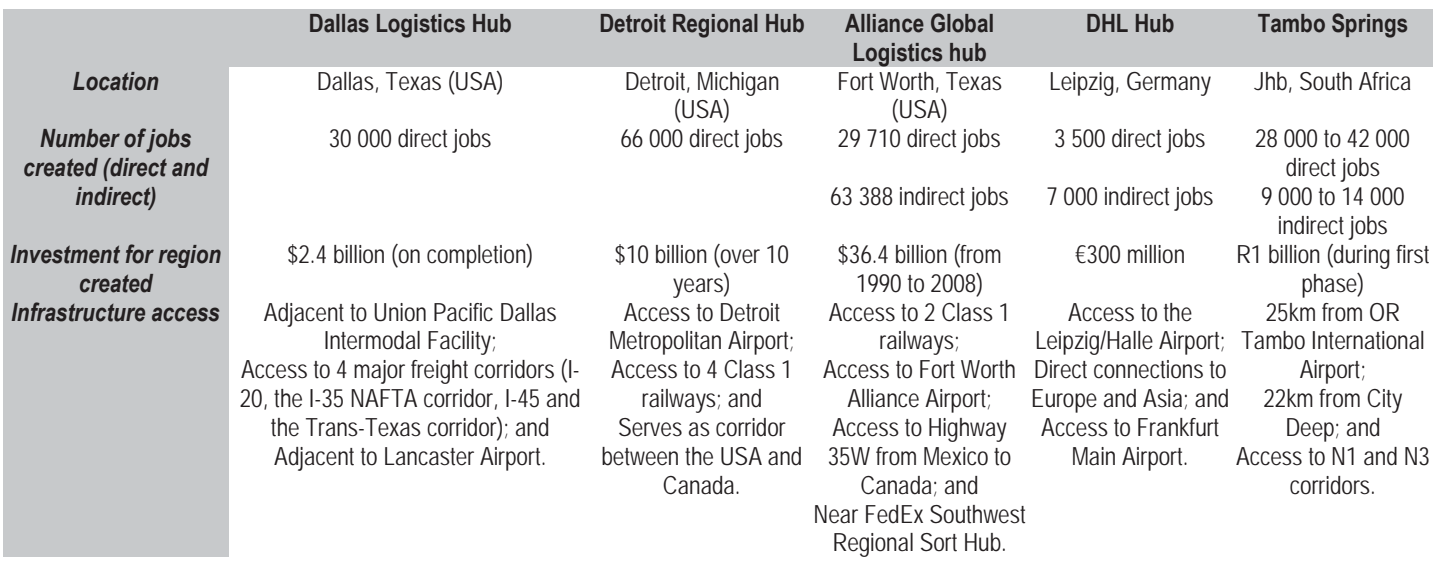

Source: Dallas Logistics Hub (DLH, 2007); Detroit Regional Chamber (DRC, 2009); Alliance Texas (1990); DHL Hub (2009); and Els (2010). 
Any development project should be aimed at developing the major manufacturing industries within the region. As discussed in the previous chapter, an investment of R 1 million would not only increase employment in all economic sectors of the Vaal but would also increase annual household income and investment in the region as a whole. The VLH would address both poverty (increasing household income) and unemployment in the Vaal, thereby increasing regional growth and development.

\section{Perceptions of Local Roleplayers: Results of the Industry Questionnaire}

In order to further highlight the need for the VLH and to promote PPPS in the Vaal region, a survey of industry roleplayers with regard to their level of participation within the VLH was conducted. For the purpose of the industry questionnaire 194 respondents were surveyed from March 2006 to August 2006 using the simple random sampling method and structured interviews, which were conducted by fieldworkers. The respondents covered a wide range of economic activities in the ELM, MLM and MMA, with a range of business sizes and economic sectors being targeted.

\subsection{Origin and destination of goods within the Vaal}

The majority of products either imported or exported into the Vaal are from or are being delivered to regions within South Africa. Of the goods within the Vaal, $73.7 \%$ has South Africa as their country of origin, while $29.9 \%$ has an international destination. Of all goods produced within the Vaal region, $70.1 \%$ has South Africa as their point of destination with $29.9 \%$ destined for an international location. Europe and Africa are the major points of destination for goods produced within the Vaal region with Africa accounting for $8.8 \%$ and Europe accounting for $7.5 \%$ of goods destined for international locations. Of the goods produced in the Vaal, only $0.5 \%$ is destined for the Middle East and $1.0 \%$ for Australasia.

As inputs to industrial activities within the Vaal, goods originating from Europe account for the greatest share (11.2\%) of the total $26.3 \%$ of all goods originating from an international destination. The second largest contributor to the production process of industries in the Vaal is North America, at $6 \%$.

Of the total volume of goods ( $73.7 \%$ of inputs) in the Vaal originating from regions within South Africa, $27 \%$ originates from the Johannesburg/Pretoria area, while $30 \%$ of goods produced in the Vaal are destined for the same region. Port Elizabeth has the lowest (0.3\%) percentage share in volume of goods that originate from the Vaal area. Of the goods that originate in South Africa (73.7\%), 32.4\% originates from the Vaal region itself.

\subsection{Modes of transport used in the Vaal}

For procurement and distribution, over half of the goods were transported by road (53\% for distribution and $56 \%$ for procurement). Rail is the second most used mode of transportation for goods within the Vaal with $34 \%$ being delivered via rail and $24 \%$ being procured using rail.

According to the survey data, of all the modes of transport, an average of $42 \%$ of the volume of goods procured from the Vaal region are shipped to their destination using containers, while an average of $47 \%$ of the volume of goods procured by undertakings within the Vaal region arrive in containers. Of the $56 \%$ and $24 \%$ of goods that are transported into the Vaal by road and rail respectively, $50 \%$ is shipped in containers. On the other hand, $40 \%$ and $35 \%$ of the volumes transported by road (40\%) and rail (35\%) to destination outside of the Vaal are shipped in containers.

\subsection{Participant perceptions regarding the VLH}

As part of the survey, respondents were asked to rate certain statements according to an opinion scale of 1 to 7 , where 1 represents "Agree strongly" and 7 represents "Disagree strongly". Those that indicated 4 on the opinion scale are considered neutral with regard to the appropriate statement. The questions can be grouped according to the following categories:

- Business specific - includes topics such as increased access to markets, increased productivity and sales and possible expansion due to increased accessibility;

- Regional contribution/impact - includes topics such as job creation, welfare, etc.;

- Import/export - covers participant opinion regarding increased import and export activity as a result of the VLH;

- Configuration - pertains to the structure of the VLH itself, namely, the VLH should contain all three proposed 
projects; and

- Support for the VLH - the extent of usage of the VLH by local role-players.

With regards to the support for the VLH, $79 \%$ of respondents indicated that they fully support the establishment of the VIA. This is echoed with $78 \%$ and $85 \%$ of respondents indicating support for the establishment of the VICD and VIDZ respectively. Overall, $85 \%$ of respondents support the establishment of the entire VLH.

As for the regional contribution or impact of the VLH, respondents indicated that there would be higher levels of job creation (92\% for the VIA and VICD and $87 \%$ for the VIDZ), higher levels of business confidence (88\%, 84\% and $87 \%$ for the VIA, VICD and VIDZ respectively) and industrial development (92\% for the VIA and VICD and 87\%for the VIDZ) within the Vaal region. Of the respondents, $83 \%$ of had indicated that the VIDZ would be the catalyst for industrial development within the region.

Interestingly, $72 \%$ of respondents had indicated that they would participate in the activities of the VICD. This would mean that respondents would be willing to relocate to the VLH in order to participate in the downstream activities of the lead firms in the region. Also, $84 \%$ of respondents believed that new business opportunities would be created by the VIDZ, which would stem from the new product and value chains that would be created through business relocation to the SDI.

Amongst the positive statements regarding the VIDZ, respondents also indicated that resource-intensive industries can be exploited as a result of the project, production activities can be further diversified (79\%) and that the project would eventually lead to an increase in the Vaal region's GGP (85\%). Of the respondents, $80 \%$ indicated that the VIDZ would reduce poverty in the region and $84 \%$ indicated that the project is an ideal LED strategy.

\section{Conclusions}

The relationship between transport and economic development is crucial to a country. As transport infrastructure becomes more efficient and reaches higher levels of investment, increased capacity, efficiency and reliability occurs. This creates time and cost savings for the industries within the region due to shortened value chains. These productivity gains are transferred to increased competitiveness which would ultimately increase economic growth. This would ensure that regions which have the greatest potential for growth within a country reap the benefits of expanded market opportunities.

A logistical hub is seen as a means of both multimodal and intermodal transportation that overcomes the economic and social challenges present within a region. Improved accessibility to markets, enhanced reliability, reduced transport costs, economies of scale, enhanced efficiency and production capacity are a few of the potential benefits that would accrue as a result of the establishment of the VLH. By taking the economic impact of other similar projects into account, then it can be assumed that the VLH would have similar results should it be implemented in the Vaal region. Of the examples given, Tambo Springs was used as a yardstick with which to measure the outcome of the establishment of the VLH. On average, it can be expected that the VLH would create between 28000 and 42000 direct jobs (those relating to the actual VLH) while 9000 to 14000 jobs would be created from the downstream activities located in the VIDZ. It can be further estimated that approximately R 1 billion in investment would be created within the Vaal region as a result of the project, thereby increasing regional growth and development.

\section{References}

Alliance Texas. (2009). Alliance Global Logistics Hub. Texas: Alliance Texas.

CSIR (Council for Scientific and Industrial Research). (2012). State of Logistics Survey for South Africa. Pretoria: CSIR.

Dewitt, W. \& Clinger, J. (1999). Intermodal freight transportation. Committee on Intermodal Freight Transport.

DHL Hub. (2009). DHL Hub Leipzig/Halle: the logistics hub that moves the world. Bonn: DHL.

DLH (Dallas Logistics Hub). 2007. Dallas Logistics Hub. Texas: DLH.

DoT (Department of Transport) see South Africa. Department of Transport.

DRC (Detroit Regional Chamber). 2009. Global logistics hub strategy. Mich.: DRC.

Els, W. (2010). Tambo Springs. Jhb.: Inframax.

Gibb, A. (2007). Gauteng freight implementation strategy. Jhb: Gauteng Provincial Government.

Goh, M. ) 2008). Issues and methods for selecting locations for logistics hubs. Central Asia Regional Economic Co-operation.

Gordhan, P. (2010). Budget Speech 2010. [Online] Available: http://www.info.gov.za/speeches/2010/10021715051004.htm (March 3, 2010).

Havenga, J. (2010). Logistics costs in South Africa - the case for macroeconomic measurement. South African Journal of Economics, 78(4):460-478.

Humphrey, J. \& Schmitz, H. (2000). Global governance and upgrading: linking industrial cluster and global value chain research. 
Brighton: Institute of Development Studies.

Jourdan, P. (1998). Spatial development initiatives - the official view. Development South Africa, 15(5), Summer.

OECD (Organisation for Economic Cooperation and Development). (2002). Impact of transport infrastructure investment on regional development. Turkey: OECD

Pienaar, W.J. (2005). Aspects of the supply or rail and road freight transport and the choice of carriers in South Africa. C.T.: University of Stellenbosch.

Rodrigue, J-P. (1998). Transportation and economic development. [Online] Available: http://people.hofstra.edu/geotrans/eng /ch7en/conc7en/ch7clen.html ( June 12, 2010).

Sedibeng District Municipality (SDM). (2010). Annual Report. Vereeniging: SDM

South Africa. Department of Transport. (1998). Moving South Africa. Pretoria : Government Printer.

South Africa. Department of Transport. (2005). National freight logistics strategy. Pretoria : Government Printer

South Africa. Department of Transport. (2007). National freight monitoring framework. Pretoria : Government Printer

Stats SA (Statistics South Africa). (2010). Gross domestic product: third quarter 2010. Pretoria: Government Printer.

The Presidency. (2007). Accelerated and shared growth initiative - South Africa (a summary). [Online] Available: http://www.info.gov.za lasgisa/asgisadoc.pdf (Oct 29, 2010).

VRG (Vaal Research Group). (2006). The Vaal Logistical Hub. Vanderbij|park: VRG. 
